كلية الطب البيطرى - جامعة البعث

سوريا

\title{
THE SURGICAL TREATMENT OF CASEOUS \\ LYMPHADENITIS IN AWASS SYRIAN SHEEP
}

(With 3 Tables and 4 Figures)

\author{
By \\ العلاج الجراحي لالتهاب العقد اللمفاوية المتجبنة في أغنام العواس السورية \\ زياد العبدالله ، طاهر اسعد \\ (Received at 20/10/2011)

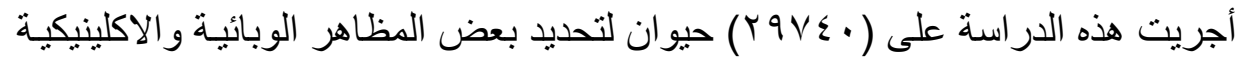

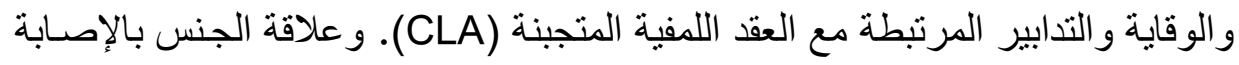

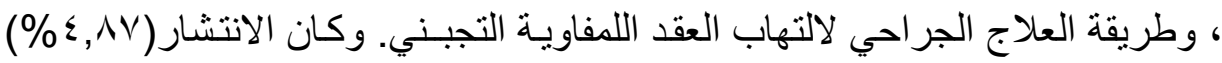 \\ في الأغنام على أساس الفحص الاكلينكي. وكان انتشار المرض أعلى العلى بكثير في الإناث

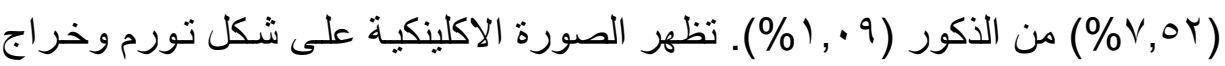

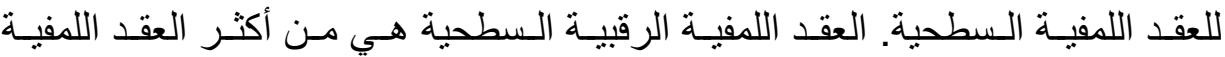

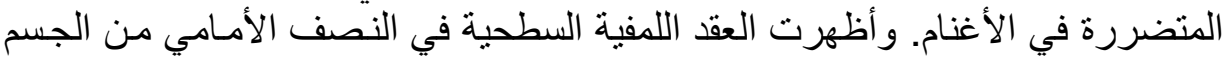

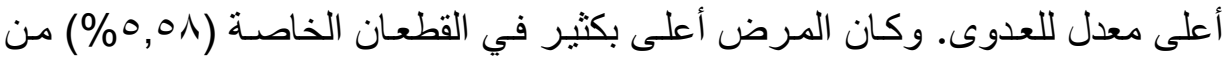 \\ القطعان الحكومية (1), • \%).
}

\section{SUMMARY}

This study was carried out on (29740) animals to determine some epidemiological, clinical and preventive measures associated with Caseous lymphadenitis (CLA). The prevalence was (4.87\%) in sheep on the basis of clinical examination. The disease prevalence was significantly higher in females $(7.52 \%)$ than in males $(1.09 \%)$. The clinical picture appeared in the form of enlargement and abscessation of the superficial lymph nodes. Superficial cervical lymph nodes were the most commonly affected nodes in sheep. The superficial lymph nodes of the anterior body half showed the highest infection rate. The disease was 
significantly higher in private flocks $(5.58 \%)$ than in governmental flocks $(0.81 \%)$.

Key words: Caseous lymphadenitis, Corynebacterium pseudotuberculosis, sheep.

\section{INTRODUCTION

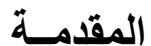

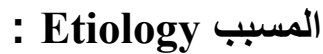

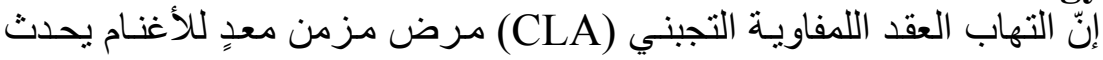

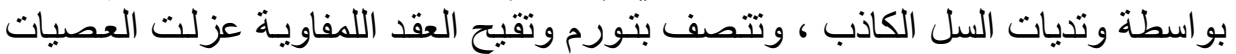

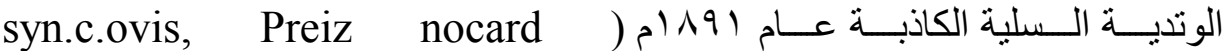
(Corynebacterium pseudotuberculosis bacillus بمرض السّل الكاذب أول مرة في فرنسا ، كما تمكن من عزل العصيات الوتديـة السلية الكاذبة من خيول مصابة بمرض التهاب الأوعية البلغية التقرحي ، و المرض فئ سجل في

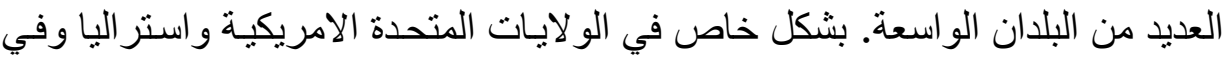

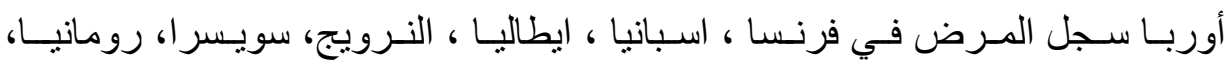

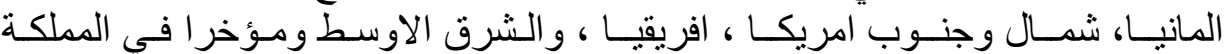

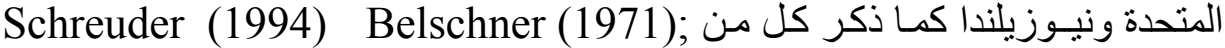
.Dorella et al. (2006) ;

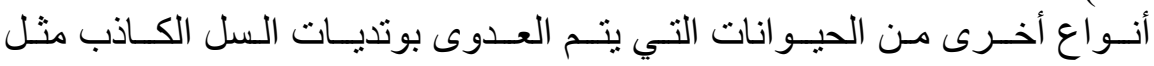
الخيـول (1974) Adekeye et al., 1980 ; Purchase, 1944 ) والماثية (Donahue, 1995 Anderson et al., 1990 ; Kariuki and Poulton, 1982 ; llamas and alpacas (Yeruham et al., 1997; Shpigel et al.,1993

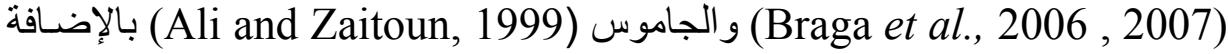
إلى ذلك ليس الخمج شـائع بوتديات السل الكاذب للإنسان ولكن سجلت في مناسبات Hill et al., 1978; Hamilton et al., 1968 ; Lopez et al., 1966) عديدة Goldberger et al., 1981 ; Keslin et al., 1979 ; Henderson, 1979 ; (Peel et al., 1997 ; Mills et al., 1997 ; House et al., 1986 ; Lambert et al., 2006 *الخمج : الإصابة أو العدوى في مصر مرض وتديـات السل الكـاذب كانت و احدة من الأمر اض المسنوطنة الرئيسية

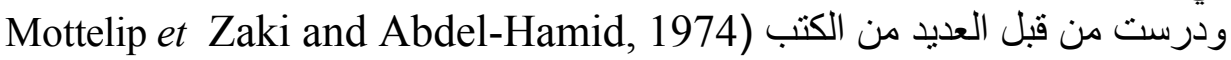
(Abd-EL-Ghani et al., 1998 ; Seddik et al., 1983 ; al., 1976 
إنّ العدوى تحدث بعد النفـاذ المتو اصل لوتديات السل الكـاذب عبر الجلد أو

الأغشية المخاطية (Fontaine and Baird, 2008; Severini and other, 2003) أو يتم نقــل الخمـج بوتديـات السـل الكـاذب عن طريـق الجهـاز التتفسي (Stoops)

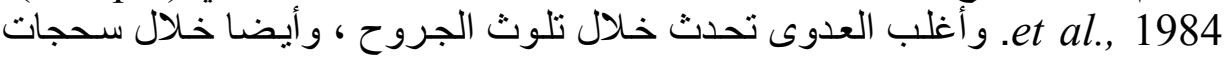

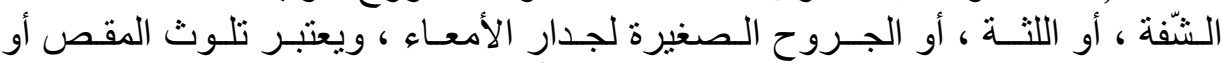

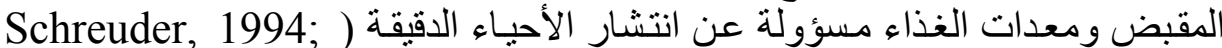

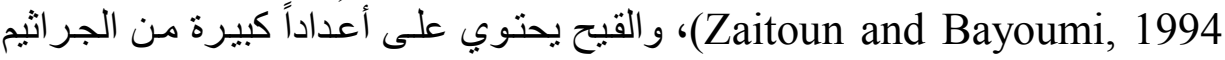
التي تبقى حية لأشـهر في التبن و المقص و التربة. ويتم خمج القطيـع بو اسطــة الاتصــال

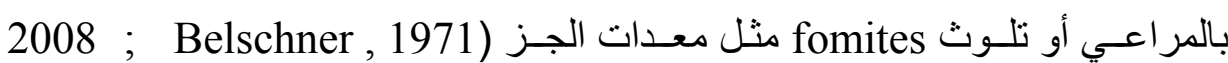

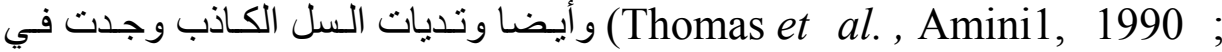

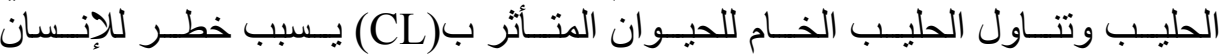
.(Goldberger et al., 1981)

Symptoms الأعراض

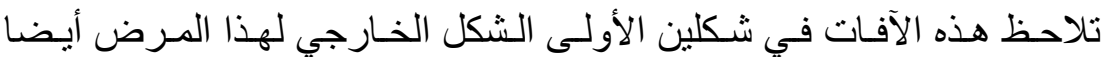

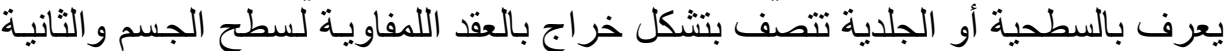

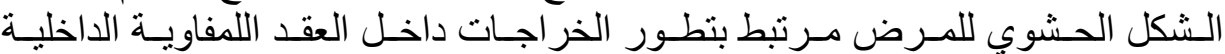

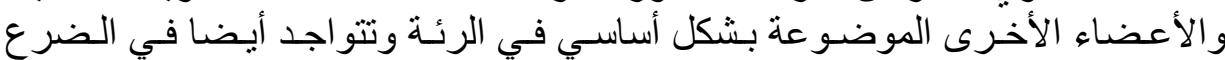
و الكبد و الكلى و الخصى و أيضا تشكل خر اجات متمحفظة تحتوي مادة متجبنة سميكة الأنس .(Aitken, 2007 ; Paule et al., 2004 ; Williamson, 2001)

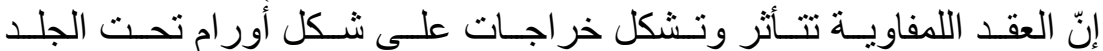

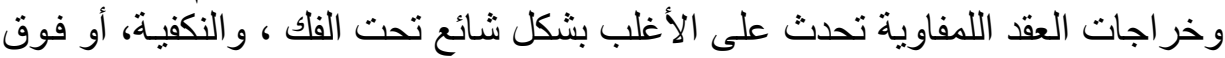

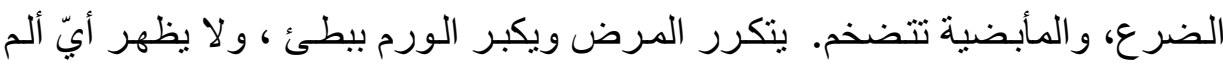

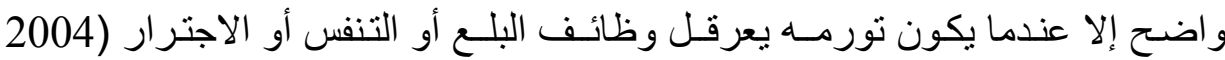
.(Paton et al., 2005 ; Baird et al., في حال إجراء مقطع عرضي في هذه العقد اللمفاوية المتجبنـة تبدو على شكل

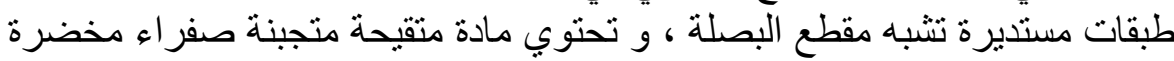
(Amini et al., 2008 ; Ben Said, 2002; Williamson, 2001; Thomas, 1990)

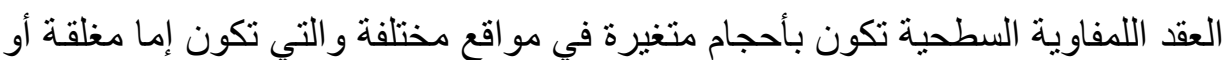
مفتوحة أو تقتح لتفرغ قيح ابيض حلبي دسم وفقد الصوف على الآفة في بعض الحالات AL-Gaabary, 2009 ; AL-Gaabary and EL-Sheikh, 2002)

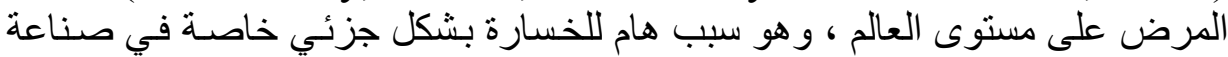

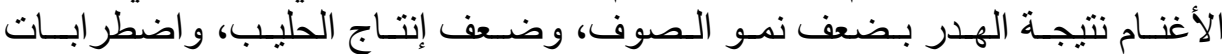

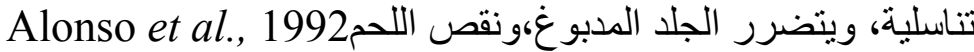


Skaika et al., 1998; Stanford et al., 1998 ; Paton et al., 1994; Burhan, 2002 ; Williamson, 2001; Conner et al., 2000 و والمرض يعتبر واحد من الأمر اض الاقتصادية الهامة للأغنـام (Baird et al., 2004

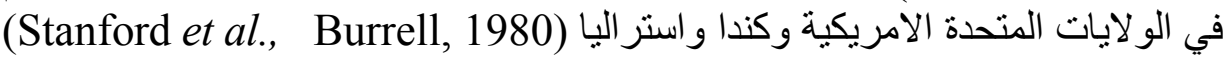

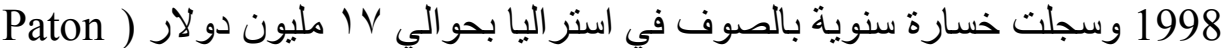
. et al., 1994

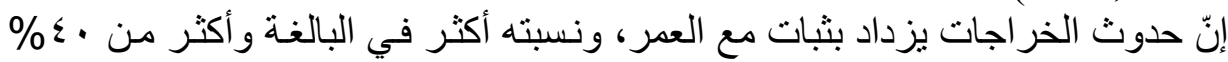

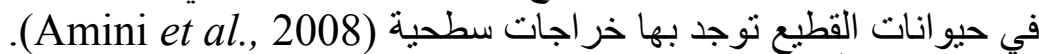

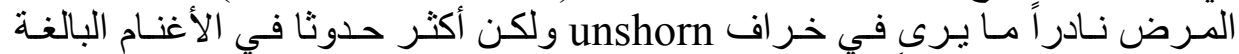

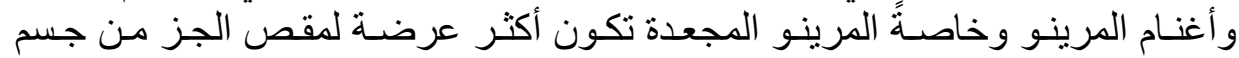
السطح المستوي وبشكل شـائع تكون أكثر تـأثر في الأغنـام مـ السلاللة البريطانيـة

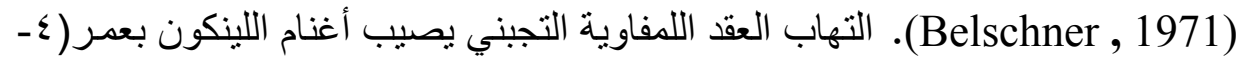

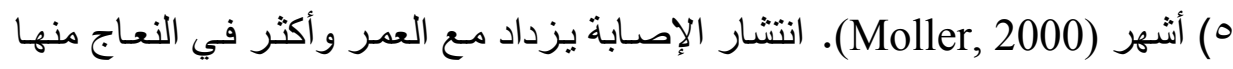
في الكباش (Arsenanlt et al., 2003).

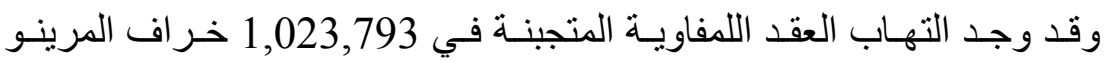
و196,737 المرينو البالغة ( 122,774 ذكور و 73,963 اناث) 946 خراف مصابة

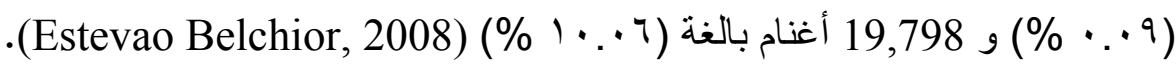

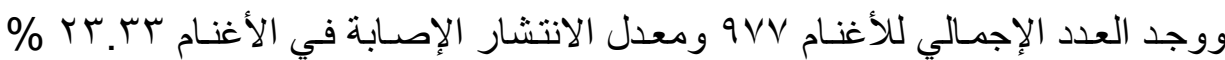

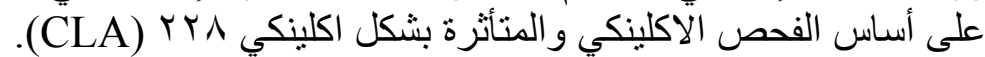

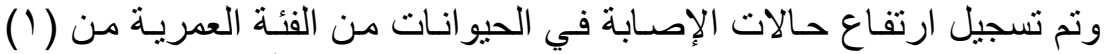

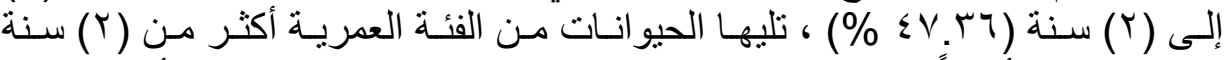

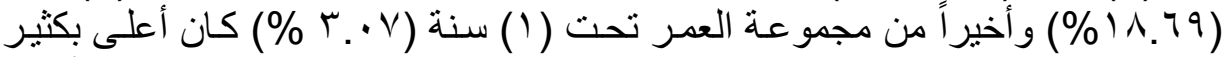

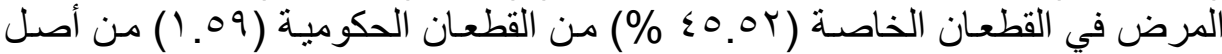

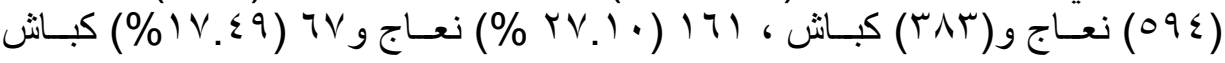

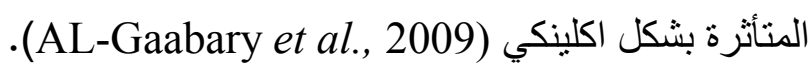

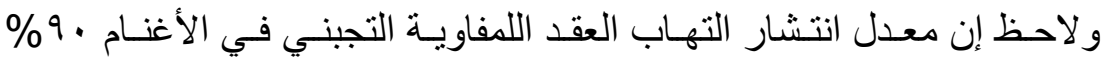
Musa, ) ومعدل الانتشـار في الأغنسام هب. (Kuria and Holstad, 1989)

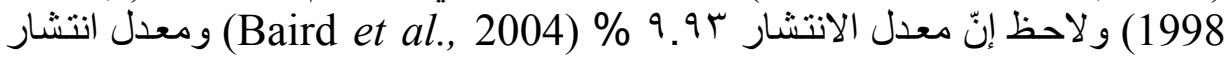

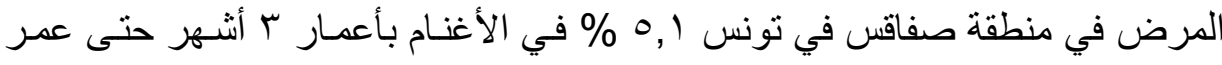

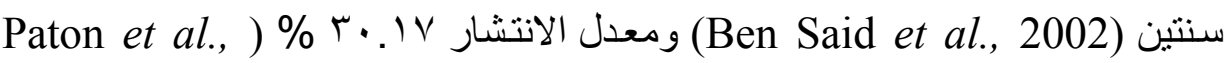

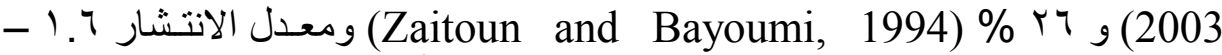

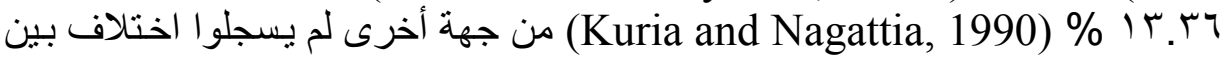

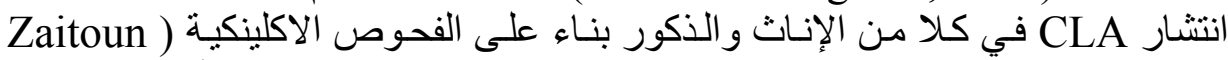

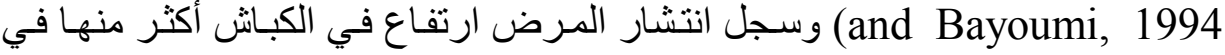




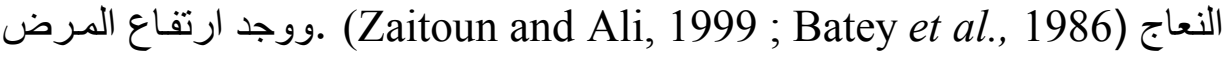

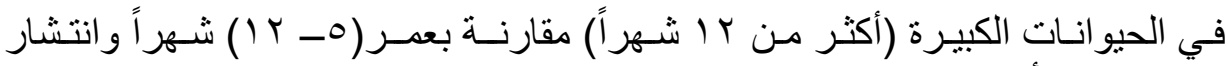

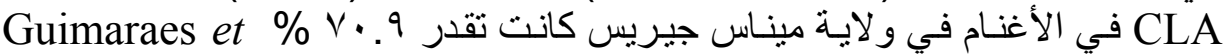
.(al., 2009)

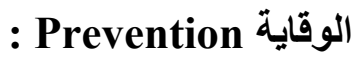

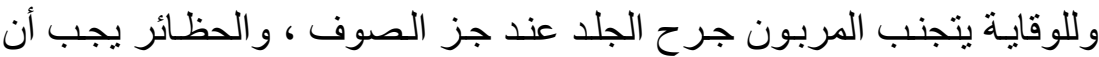

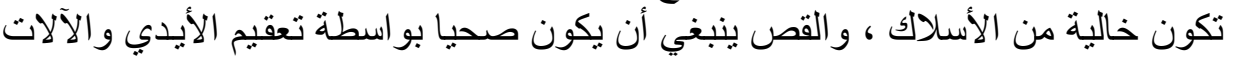

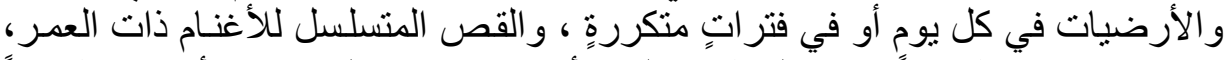

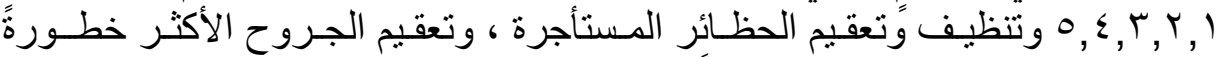

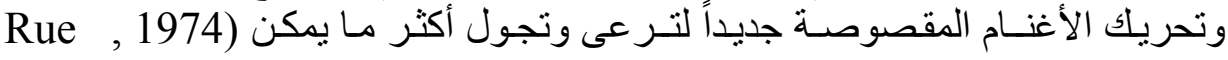

.(Jesen

\section{العلاج Treatment}

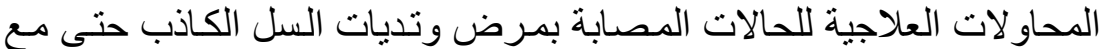

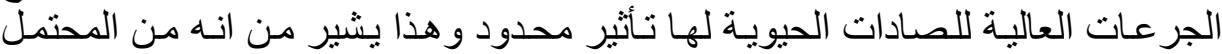

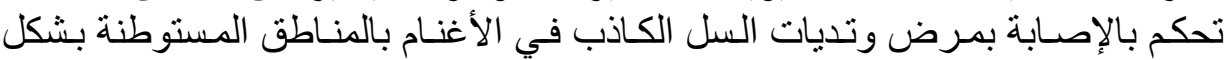

خاص (Laven et al., 1997).

رغم إن الميكروبـات حساسة للبنسلين. فـالعلاج بالمضاد الحيوي عـادة ليس

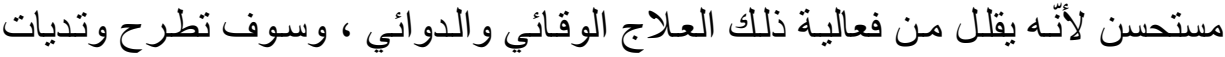
السل الكاذب المعدية للقطيع و الأفر اد (Batey et al., 1986).

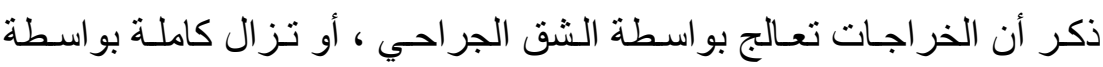

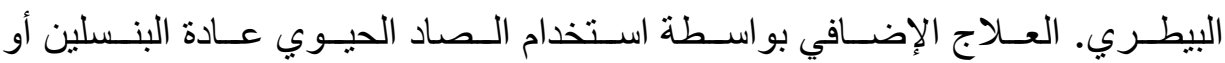
التتر اسكلين يستمر لمدة ب إلى ه أيام. التهاب العقد اللمفاوية التجبني ينتشر بشكل بطي التي

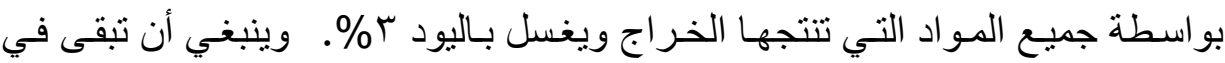

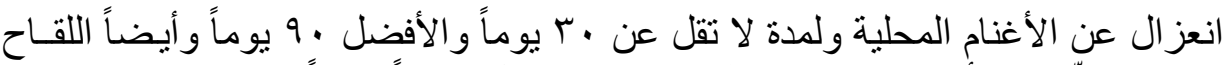

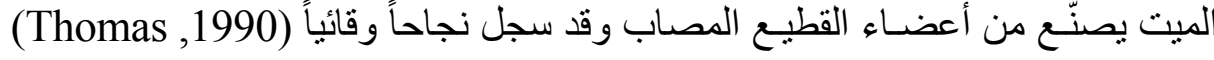

لكن (1970) Belscher وجد بإنّ علاج المرض ليس ممكن عمليا رغم تكبر

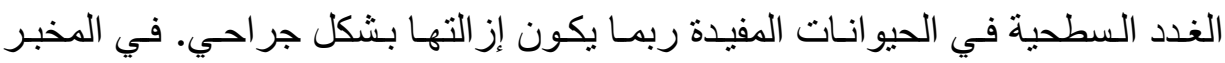

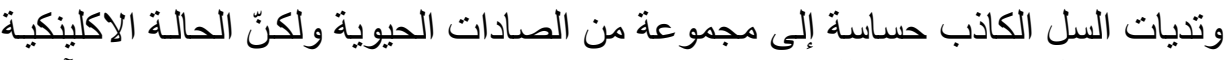

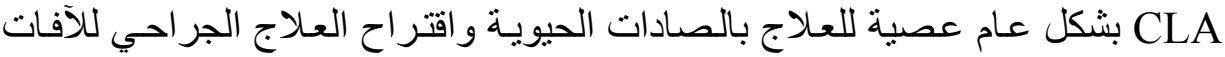

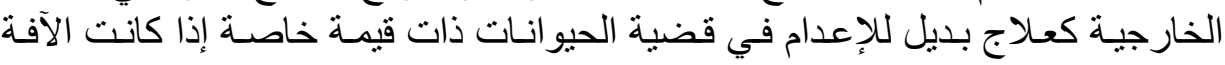




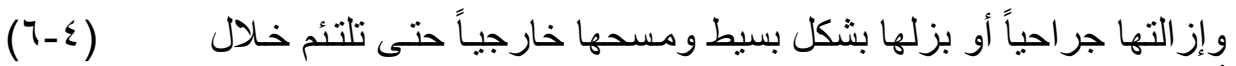

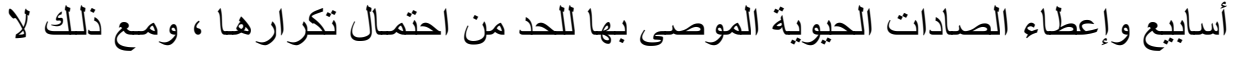
يمكن الاعتمـاد على الصاد الحيوي لإز الـة جميع مسببات الأمـر اض لمعالجة الآفـات. والآفات الداخلية غير الموجودة في كثير من أنحاء العالم. واتخذت التدابير للسيطرة

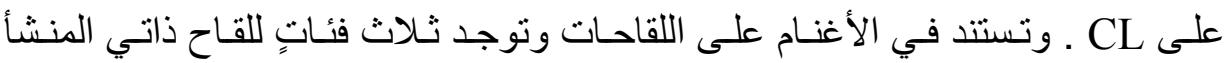

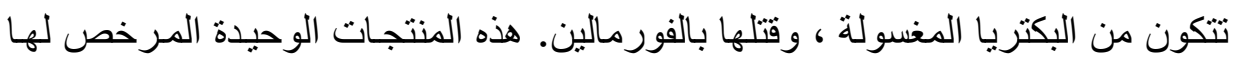

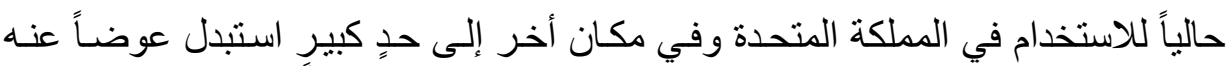

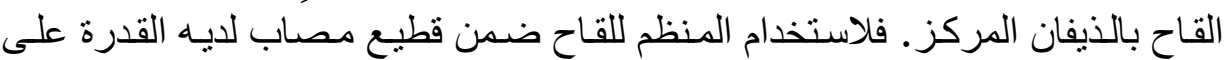

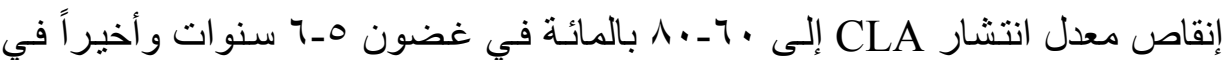

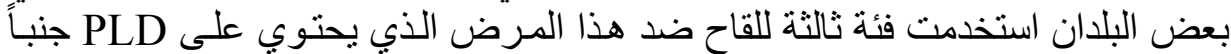

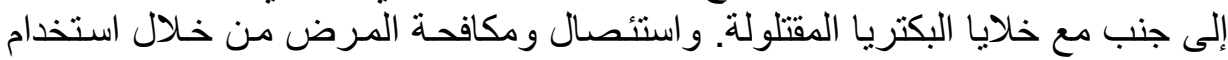
الأمصال تلقى اهتماماً كبير اً في هولندا (Aitken, 2007).

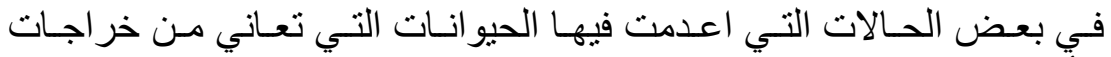

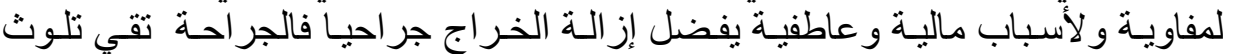

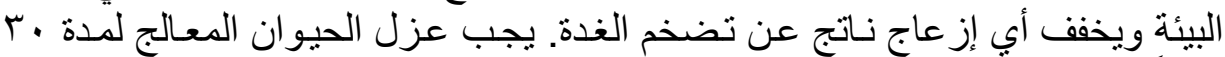

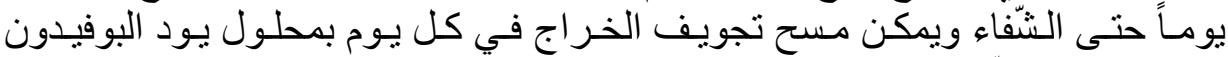

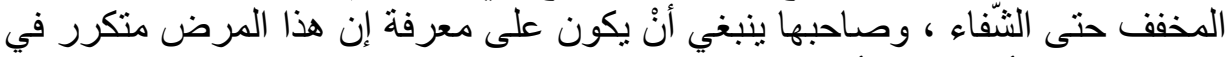

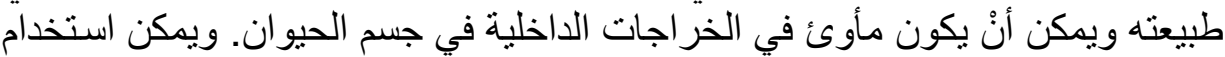

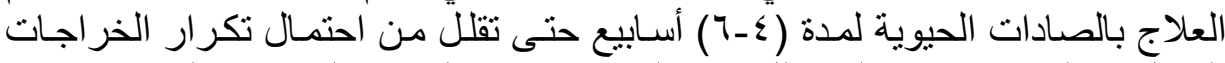

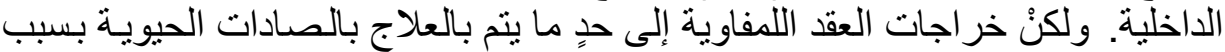

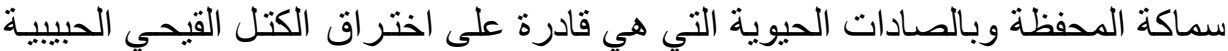

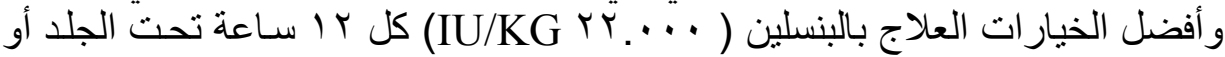

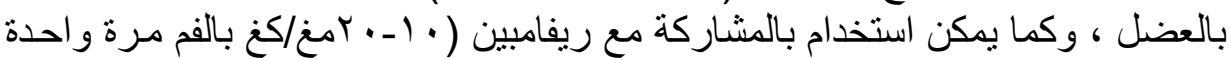
يوميا) لاذابة الدهون بدرجة عالية. بالية

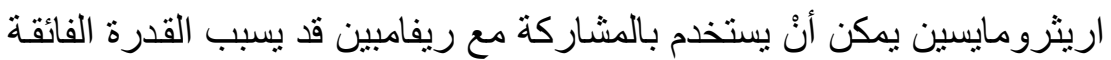

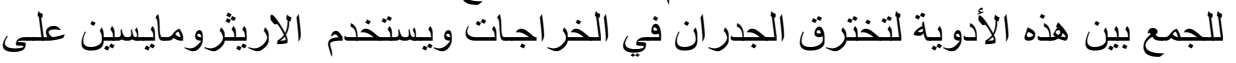
شكل حقن ويفضل عن طريق الفم لأنه لا يتعرض للتغيير في الجهاز الهضدئ فئري كثيراً.

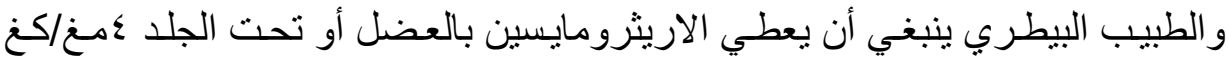

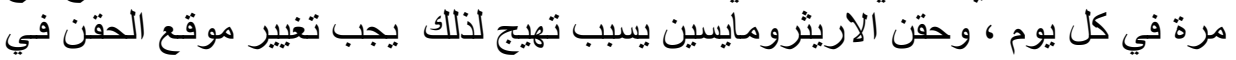

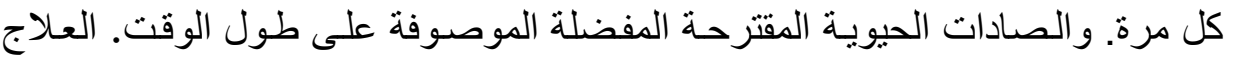

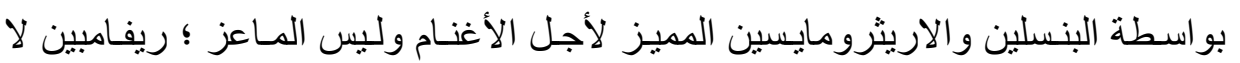

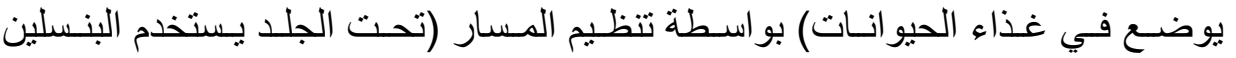

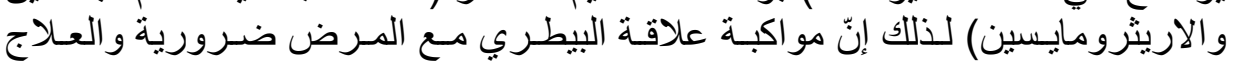


يحتـاج إلى فتر ات طويلـة بمـا فيها الكفايـة. وحقن الفورمـالين داخل الخراج هي تقنية

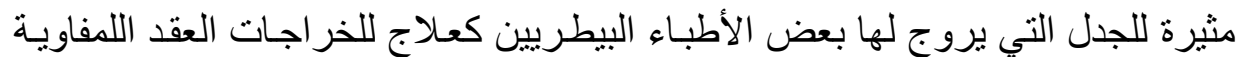

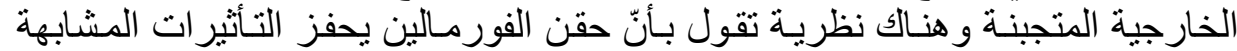

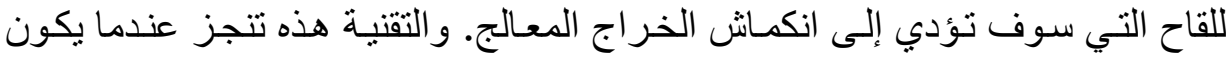

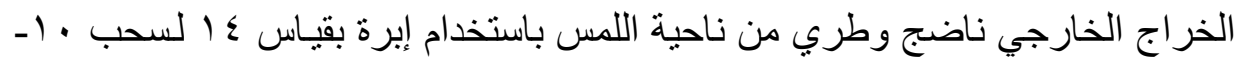

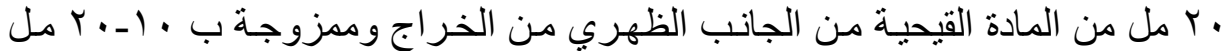

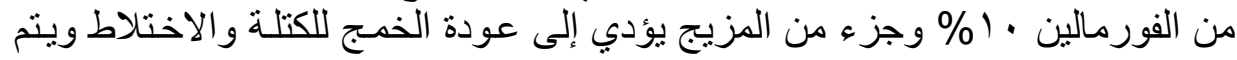

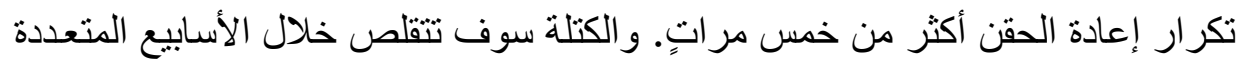
القليلة. هذا العلاج له مساوئ عدة. ومن أخطار الفورمالين يسبب السرطان. و الأطباء

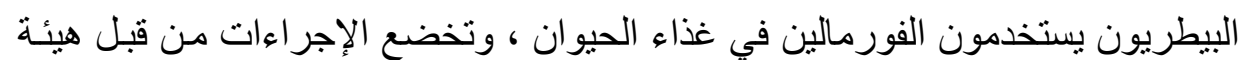

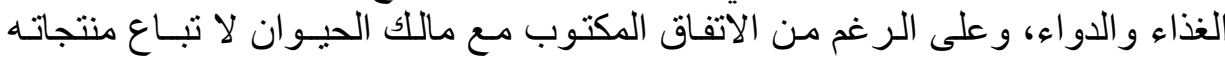
(الحليب منها) للاستهلاك البشري (Williamson, 2001).

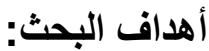
1- معرفة انتشار الإصابة وارتباطها بالجنس. r- طريقة العلاج الجر احي لالتهاب العقد اللمفاوية المتجبنة.

\title{
MATERIALS and METHODS
}

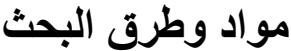

\begin{abstract}
: Animals الحيوانات

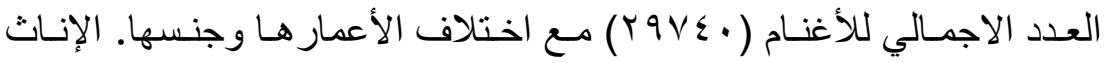

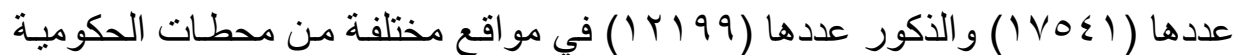

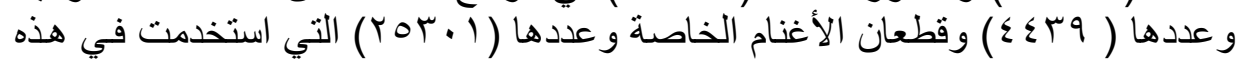
الدراسة. بعض هذه الأغنام تعاني من خر اجات سطحية في العقد اللمفاوية في جسمها.
\end{abstract}

\section{العلاج الجراحي Surgical treatment :}

إعطاء مهدئ زيلازين هيدروكلوريد بالعضل بمقدار ب, · مـغ/كغ ثم حلاقة

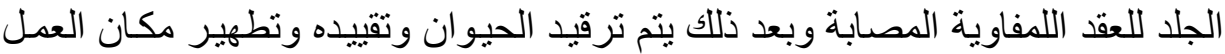

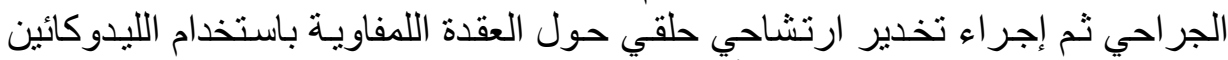

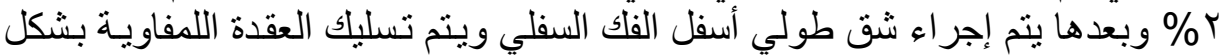
حذر و إيقاف نزف الأوعية بواسطة القو ابض الثريانية ويتم خياطة الجلد بخيط الحرير

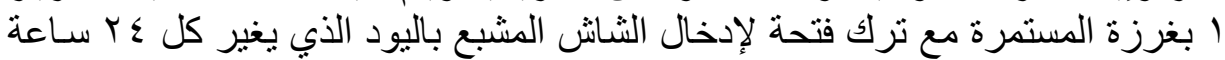




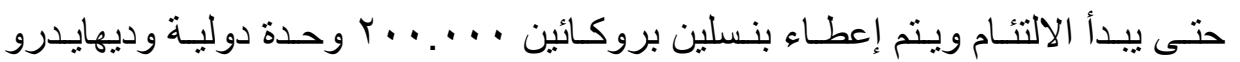

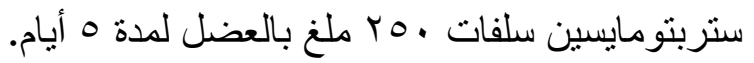

صور توضح الأعراض الاكلينكية للإصابة بالتهاب العقد اللمفاوية المتجبنة
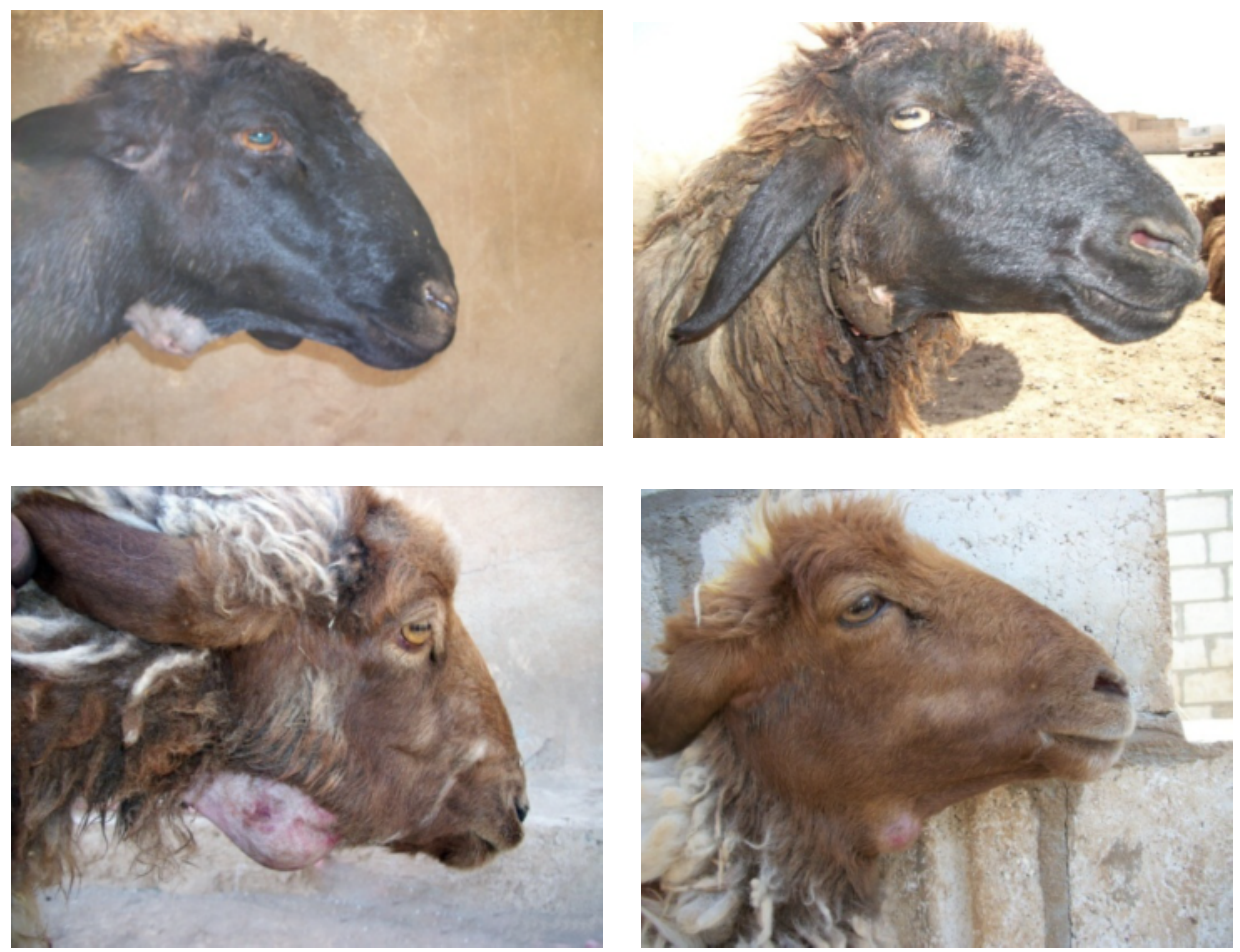

الخطوات للاستئصال الجراحي للعقد اللمفاوية المتجبنة عند أغنام العواس 


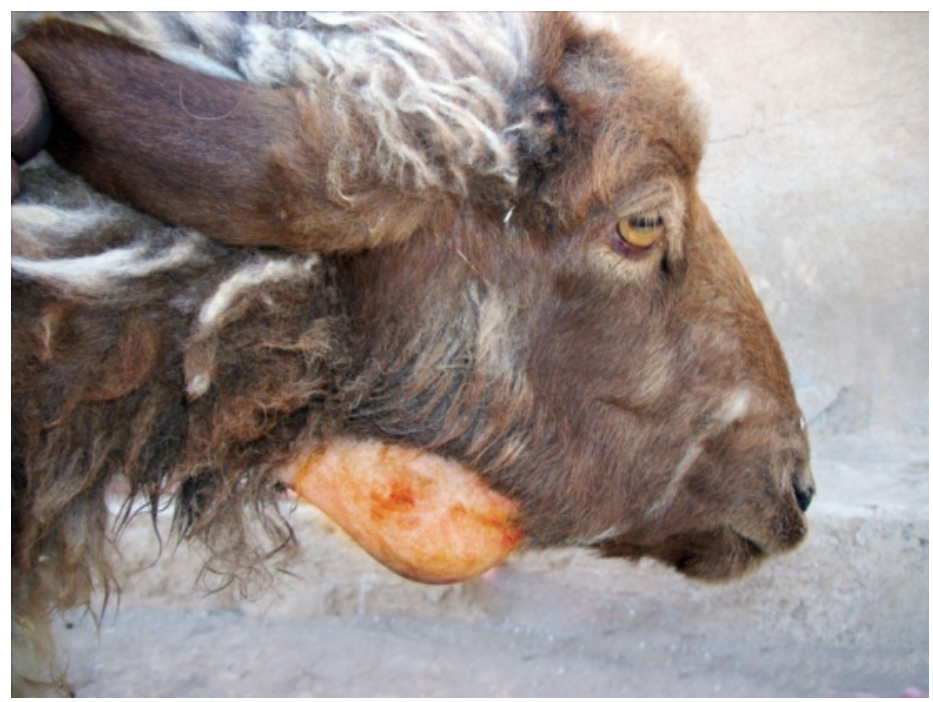

شكل رقم (1)

العقدة اللمفاوية تحت فكية مصابة بالتهاب العقد اللمفاوية التجبني

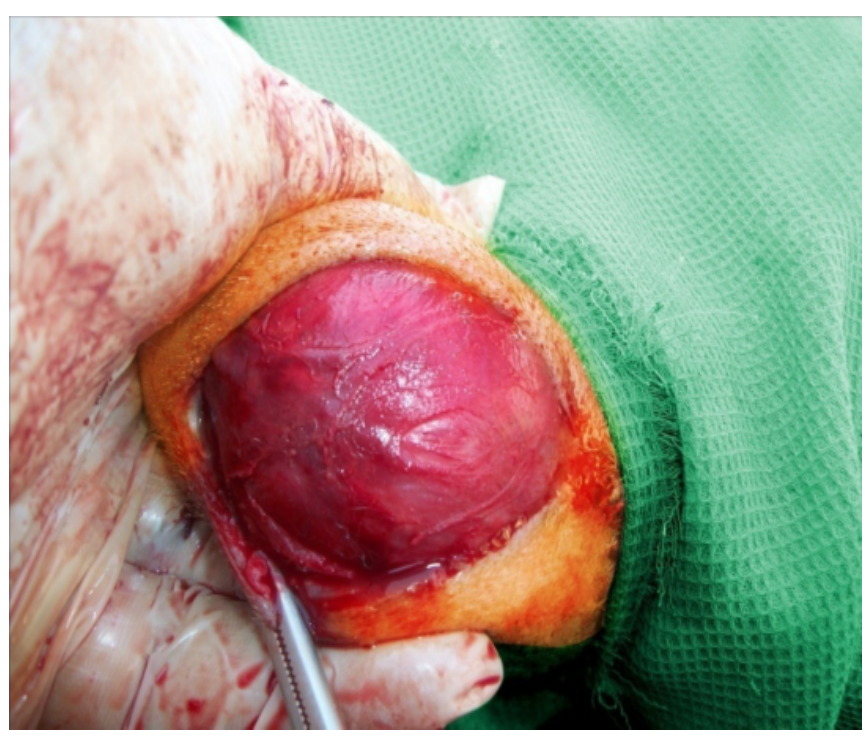

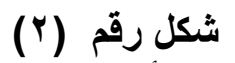
إجراء شث طولي أسفل القك السفلي

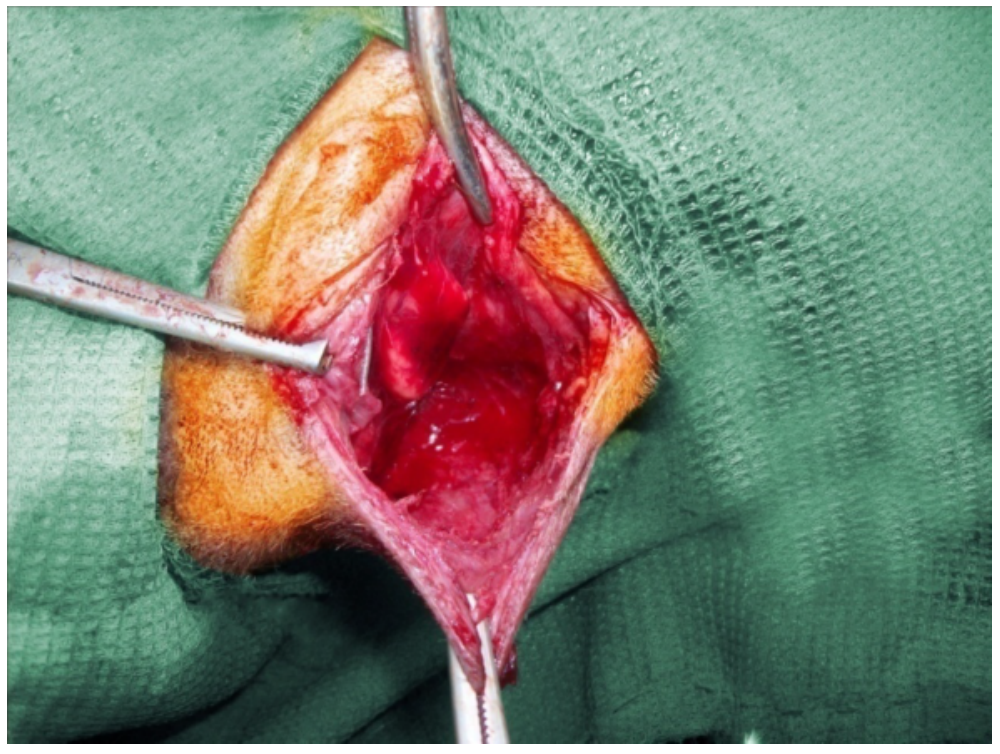




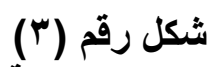

استخراج العقدة اللمفاوية من مكانها

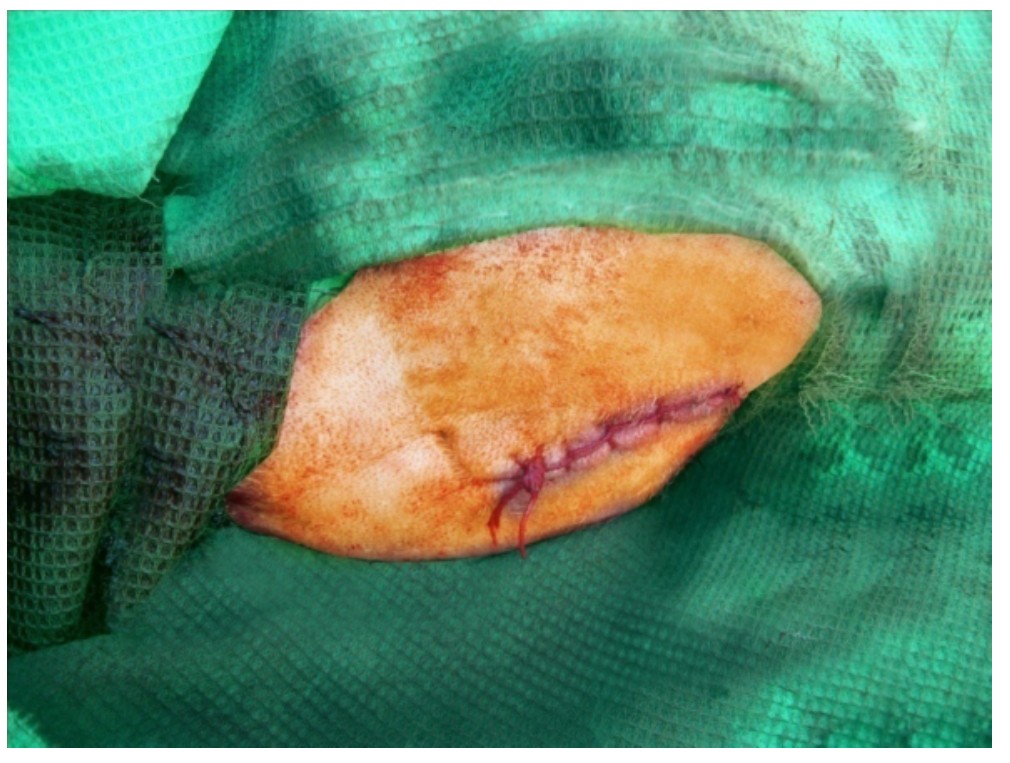

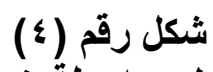

خياطة الجلد بواسطة خيط الحرير

RESULTS

النتائج 
Assiut Vet. Med. J. Vol. 58 No. 132 January 2012

\begin{tabular}{|c|c|c|c|}
\hline الانتشار \% & المصسابة & العدد & الجنس \\
\hline 7.52 & 1320 & 17541 & إناث \\
\hline 1.09 & 130 & 12199 & ذكور \\
\hline 4.87 & 1450 & 29740 & إجمالي \\
\hline
\end{tabular}

جدول (1)

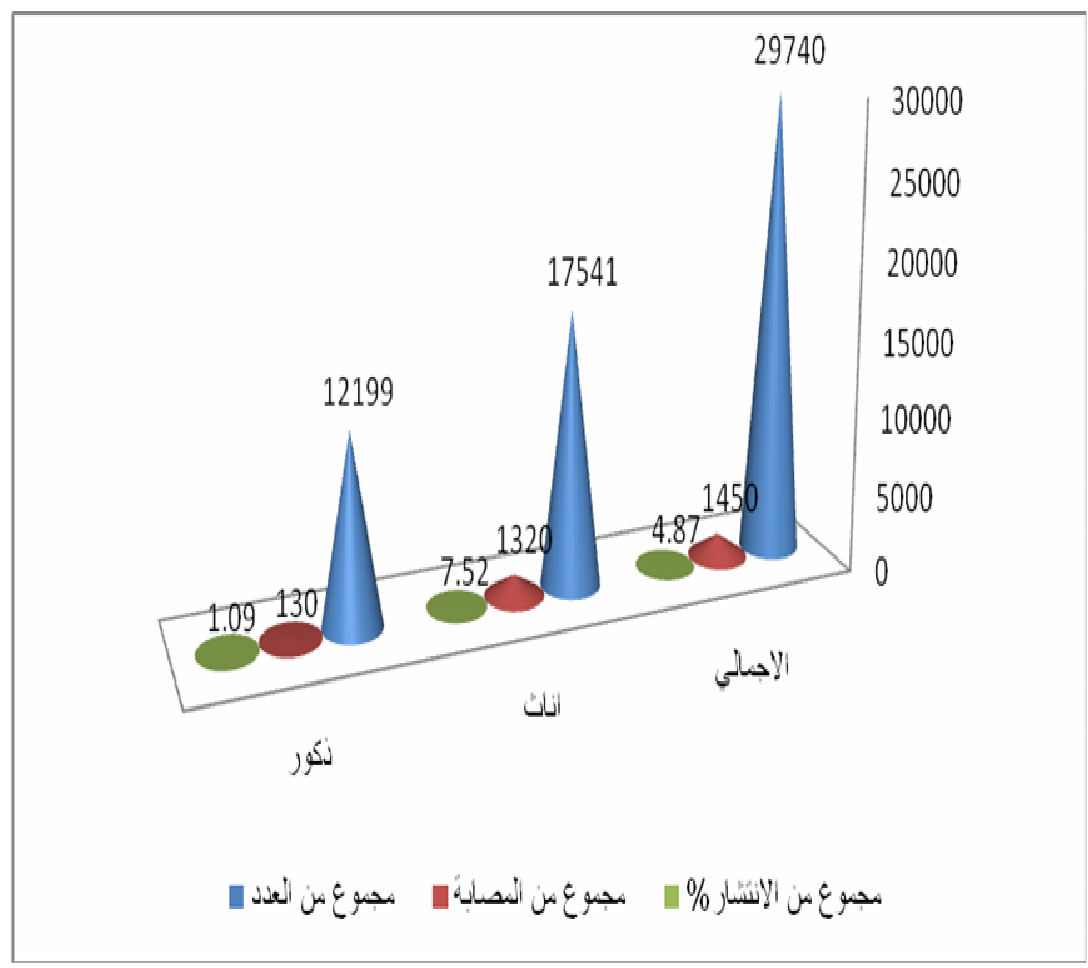

المخطط (1) يبين : انتشار الإصابة بالتهاب العقد اللمفاوية حسب الجنس 
Assiut Vet. Med. J. Vol. 58 No. 132 January 2012

\begin{tabular}{|c|c|c|c|}
\hline الانتشار \% & المصابة & العدد & الجنس \\
\hline 8.73 & 1290 & 14771 & إناث \\
\hline 1.17 & 124 & 10530 & ذكور \\
\hline 5.58 & 1414 & 25301 & مالى \\
\hline
\end{tabular}

جدول (Y)

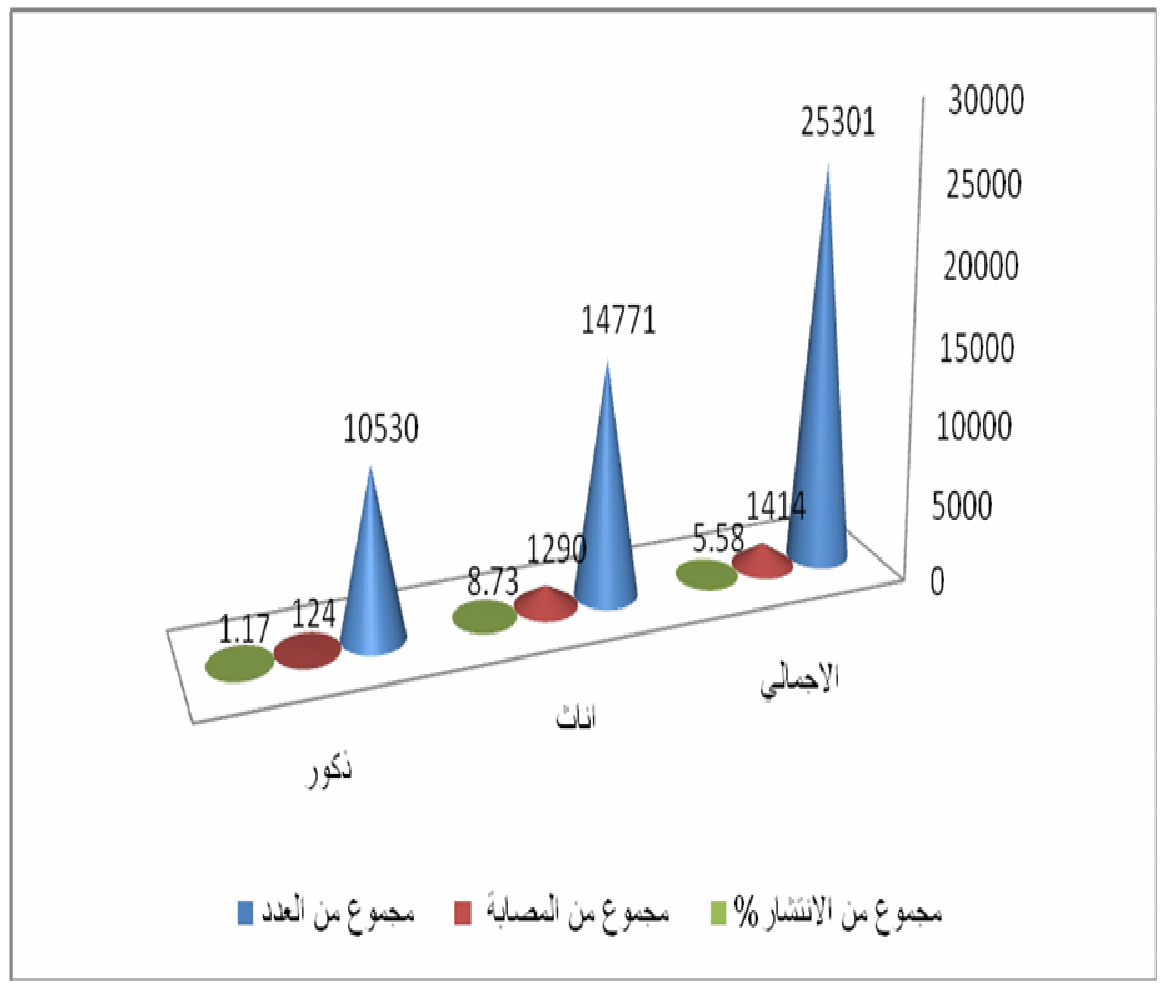

المخطط (ץ) يبين : انتثار الإصابة في المزارع الخاصة حسب الجنس 
Assiut Vet. Med. J. Vol. 58 No. 132 January 2012

\begin{tabular}{|c|c|c|c|}
\hline الانتشار \% & المصابة & العدد & الجنس \\
\hline 1.08 & 30 & 2770 & إناث \\
\hline 0.35 & 6 & 1669 & ذكور \\
\hline 0.81 & 78 & 4439 & إجمالي \\
\hline
\end{tabular}

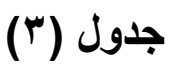

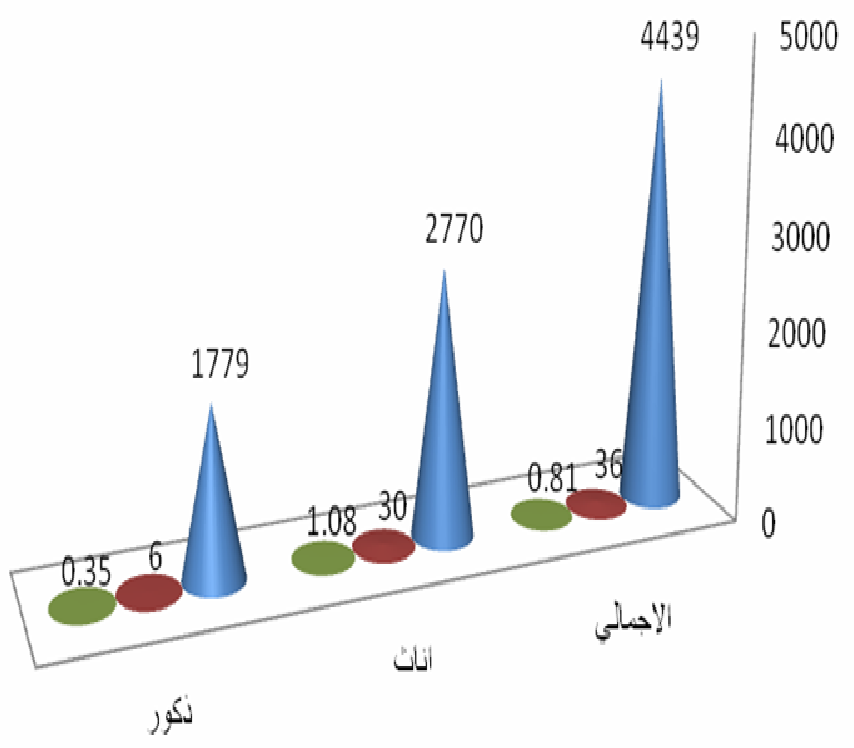

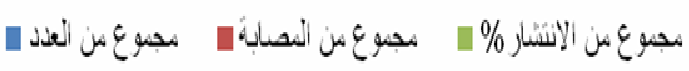

المخطط (ץ) يبين : انتثار الاصابة بالعقد اللمفاوية المتجبنة في المحطات الحكومية

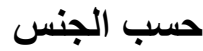

\section{DISCUSSION}

المناقشـة 
التهاب العقد اللمفاوية التجبني هو مرض مزمن للمجترات الصغيرة ، ينتشر

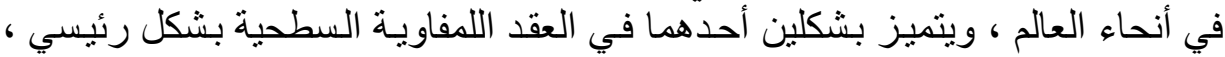
ونادر ا في العقد اللمفاوية الحشوية والأعضاء (Paule et al., 2004).

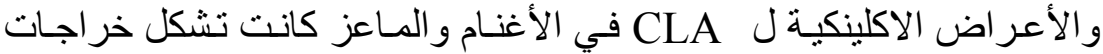
بالعقد اللمفاوية السطحية بأحجام متغيرة في مواقع مختلفة ، و التي قد تكون إمـا مغلقة أو أو الت

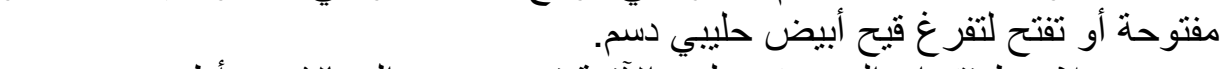

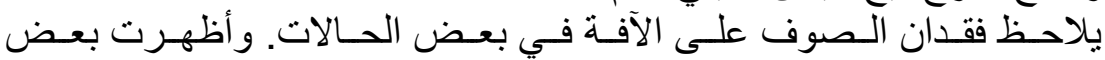

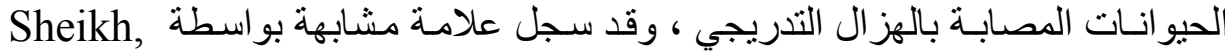
.(AL-Gaabary and EL- 2002)

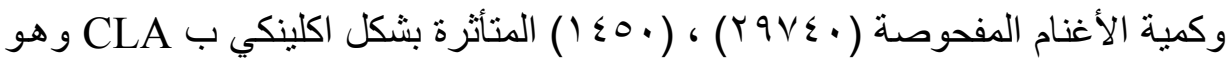

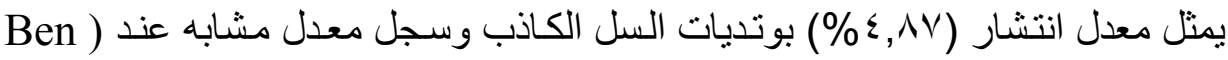

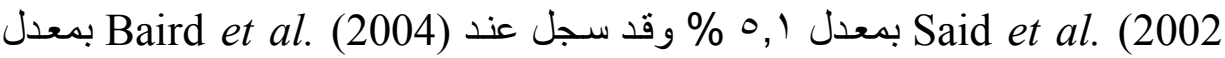

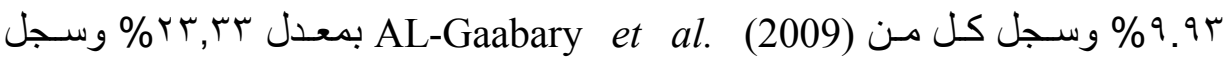

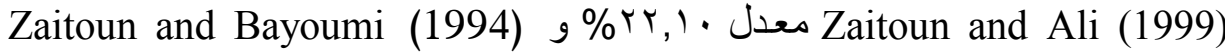
سجلا معدل انتشار Paton (2003) and

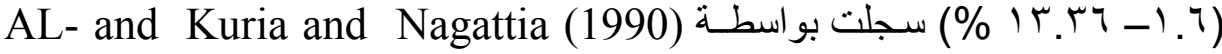
.Gaabary and EL- Sheikh (2002) ; Mubarak et al. (1999) وقد لوحظ وجود فرق بين الجنسين في انتشار CLA في أغنام العواس بناء

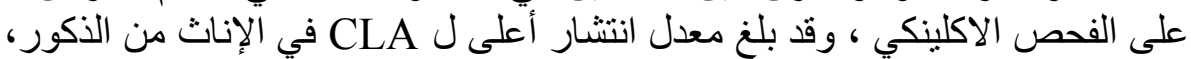

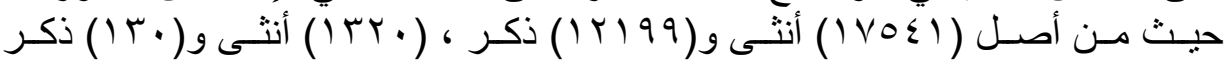

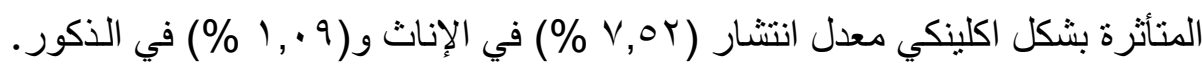
سجلا ارتفاع في انتشار في Belchior (2008) , Zaitoun and Ali (1999)

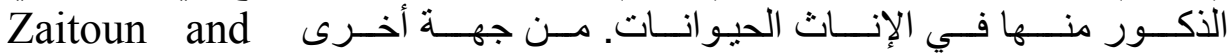

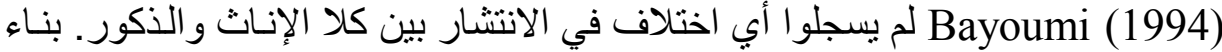

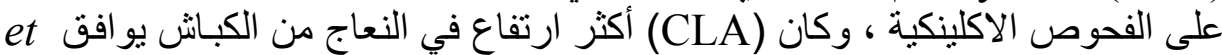
Batey et al. وسجل Gaabary et al. (2009) ; Arsenanlt al. (2003) (1986) أكثر ارتفاع في الكباش منها في النعـاج. آليـة حدوث هذه الآفات تبدأ بعد

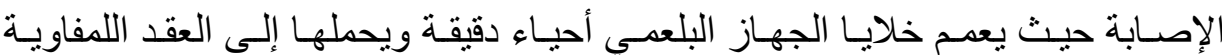

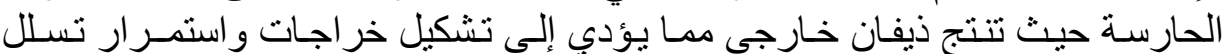

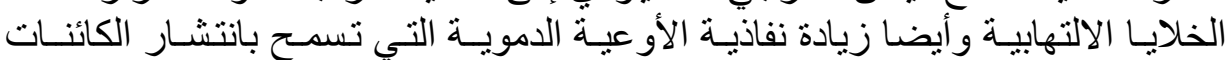
الحية إلى الغدد اللمفاوية والأعضاء الحشوية (Baird and Fontaine, 2007). 


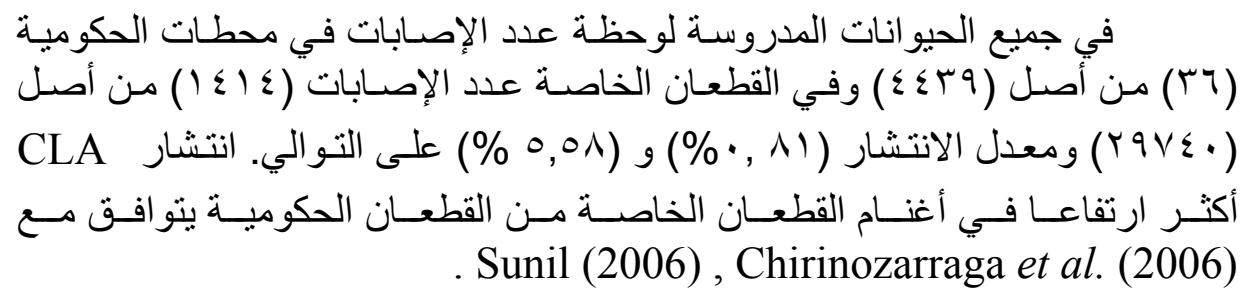

\section{REFERENCES}

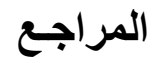

Abd EL-Ghani, M.M.; El-Jakee, J. and Saweris, Y.S. (1998): Bacteriological and serological studies on Corynebacterium pseudotuberculosis in sheep and goats J. Egypt. Vet. Med. Assoc. 58: 111-125.

Addo, P.B.; Wilcox, G.E. and Taussig, R. (1974): Mastitis in a mare caused by Corynebacterium ovis. Vet. Rec. 95, 193.

Adekeye, J.D.; Shannon, D. and Addo, P.B. (1980): Mastitis in a cowcaused by Corynebacterium pseudotuberculosis (C. ovis). Vet. Rec. 106, 270.

Ali, H.S. and Zaitoun, A.M. (1999): Studies on cutaneous suppurative lymphangitis in buffaloes at Assiut Governorate-Egypt. Assiut. Vet. Med. J. 41: 208-222

AL-Gaabary, M.H. and EL-Sheikh, W.M.A. (2002): Epidemiological, clinical and preventive studies on caseous lymphadenitis in sheep and goats at Gharbia governorate. In: $10^{\text {th }}$ Sci. Cong. Fac. Vet. Med. Assiut University Egypt, pp, 402-417.

Alonso, J.L.; Simon, M.C.; Girones, O.; Muzquiz, J.L.; Ortega, C. and Garcia, J. (1992): The effect of experimental infection with Corynebacterium pseudotuberculosis on reproduction in adult ewes. Res. Vet. Sci. 52: 267-272.

Amini, F.; Sadegipanah, A. and Babaei, M. (2008): A Study on the Prevalence of Caseous Lymphadenitis in sheep, Bangkok, Thailand, Proceedings, the $10^{\text {th }}$ Congress of FAVA-OIE Symposium on Emerging Diseases, 27-30 October.

Anderson, M.L.; Lean, I.J. and Blanchard, P.C. (1990): Corynebacterium pseudotuberculosis associated skin disease of Holstein cattle in the San Joaquin Valley, California. Bov. Pract. 25: 73-75. 
Arsenault, J.; Girard, C.; Dubreuil, P.; Daignault, D.; Galarneau, JR.; Boisclair, J.; Simard, C. and Belanger, D. (2003): Prevalence of and carcass condemnation from maedi-visna, paratuberculosis and caseous lymphadenitis in culled sheep from Quebec, Canada. Prev. Vet. Med. May 30, 59 (1-2) 68-81.

Baird, G.J. and Fontaine, M.C. (2007): Corynebacterium pseudotuberculosis and its role in ovine caseous lymphadenitis. J. Comp. Pathol. 137, 179-210.

Baird, G.J.; Malone, F.E. and Kamp, E.M. (2004): The use of serological testing to control and eradicate caseous lymphadenitis (CLA) with sheep flocks. Proceeding of theSheep Veterinary Society 2003, 27, 45-46. Published 2004.

Baird, G.; Synge, B. and Dercksen, D. (2004): Survey of caseous lymphadenitis seroprevalence in British terminal sire sheep breeds. Vet. Rec. 154, 505-506.

Batey, R.G.; Speed, C.M. and Kobes, C.J. (1986): Prevalence and distribution of Caseous lymphadenitis in feral goats. Aust. Vet. J. 63: 33-36.

Belschner, H.G. (1971): Sheep Management and Diseases. National library of Australia, Ninth edition, Sydney, $838 \mathrm{p}$.

Ben Said, MS.; Ben Maitigue, H.; Benzarti, M.; Messadi, L.; Rejeb, A. and Amara, A. (2002): Epidemiological and clinical studies of ovine Caseous lymphadenitis. Arch Inst Pasteur Tunis. 79 (1-4) 51-7.

Braga, W.; Schul, S.; Nũnez, A.; Pezo, D. and Franco, E. (2007): A primary Corynebacterium pseudotuberculosis lowdose infection in alpacas (Lama pacos) protects against a lethal challenge exposure. Small Rumin. Res. 72: 81-86.

Braga, W.U.; Chavera, A. and Gonzalez, A. (2006): Corynebacterium pseudotuberculosis infection in highland alpacas (Lama pacos) in Peru. Vet. Rec. 159: 23-24

Burhan Cetinkaya; Murat Karahan; Eray Atil; Recep Kalin; Thierry De Baere and Mario Vaneechoutte (2002): Identification of Corynebacterium pseudotuberculosis isolates from sheep and goats by PCR. Veterinary Microbiology 88: 75-83.

Burrell, D.H. (1980): A simplified double immunodiffusion technique for detection of Corynebacterium ovis antitoxin. Res. Vet. Sci. 28: $234-237$. 
Chirinozarraga, C.; Scaramelli, A. and Reyvaleiron, C. (2006): Bbacteriological characterization of Corynebacterium pseudotuberculosis in Venezuelan goat flocks small Rumin. Res. 65: 170-175.

Conner, K.H.; Quirie, M.M.; Baird, G. and Donachie, W. (2000): Characterization of United Kingdom isolates of Corynebacterium pseudotuberculosis using pulsed field gel electrophoresis. J. Cli. Microbiol. 38: 2633-2637.

Dercksen, DP.; Brinkhof, JM.; Dekker-Nooren, T.; Maanen, K.; Bode, CF.; Baird, G.; Kamp, EM. (2000): A comparison of four serological test for the diagnosis of Caseous lymphadenitis in sheep and goats. Vet. Microbiol. Jul. 31, 75 (2): 167-75.

Dorella, F.A.; Pacheco, L.G.C. and Oliveria, S.C. (2006): Corynebacterium pseudotuberculosis: microbiology, biochemical properties, pathogenesis and molecular studies of virulence. Vet. Res. 37: 201-218.

Goldberger, A.C.; Lipsky, B.A. and Plorde, J.J. (1981): Suppurative granulomatous lymphadenitis caused by Corynebacerium ovis (pseudotuberculosis). Am. J. Clin. Pathol. 76: 486-490.

Goldberger, A.C.; Lipsky, B.A. and Plorde, J.J. (1981): Suppurative granulomatous lymphadenitis caused by Corynebacterium ovis (pseudotuberculosis). Am. J. Clin. Pathol. 76: 486-490.

Guimaraes. A.S.; Seyffert, N.; Bastos, B.L.; Portela, R.W.D.; Meyer, R.; Carmo, F.B.; Cruz, J.C.M.; McCulloch, J.A.; Lage, A.P.; Heinemann, M.B.; Miyoshi, A.; Azevedo, V. and Gouveia, A.M.G. (2009): Caseous lymphadenitis in sheep flocks of the state of Minas Gerais, Brazil: Prevalence and management surveys. Small Ruminant Research 87, 86-91.

Hamilton, N.T.; Perceval, A.; Aarons, B.J. and Goodyear, J.E. (1968): Pseudotuberculous axillary lymphadenitis caused by Corynebacterium pseudotuberculosis. Med. J. Aust. 2: 356-361

Henderson, A. (1979): Pseudotuberculous adenitis caused by Corynebacterium pseudotuberculosis. J. Med. Microbiol. 12: 147-149.

Hill, L.R.; Lapage, S.P. and Bowie, I.S. (1978): Computer identification of coryneform bacteria. In: Bousefield, I.J., Callely, A.G. (Eds.), Coryneform Bacteria. Academic Press, London, pp. $181-215$. 
House, R.W.; Schousboe, M.; Allen, J.P. and Grant, C.C. (1986): Corynebacterium ovis (pseudotuberculosis) lymphadenitis in a sheep farmer: a new occupational disease in New Zealand. N. Z. Med. J. 99: 659-662

Aitken, I.D. (2007): Diseases of sheep. Fourth Edition.

Join-Lambert, O.F.; Ouache, M.; Canioni, D.; Beretti, J.-L.; Blanche, S.; Berche, P. and Kayal, S. (2006): Corynebacterium pseudotuberculosis necrotizing lymphadenitis in a twelve-yearold patient. Pediatric. Infect. Dis. J. 25: 848-851

Kariuki, D.P. and Poulton, J. (1982): Corynebacterium infection of cattle in Kenya. Trop. Anim. Health Prod. 14: 33-36.

Keslin, M.H.; McCoy, E.L.; McCusker, J.J. and Lutch, J.S. (1979): Corynebacterium pseudotuberculosis. A new cause of infectious and eosinophilic pneumonia. Am. J. Med. 67: 228-231.

Kuria, J.K. and Holstad, G. (1989): A seroepidemiological investigation of Corynebacterium pseudotuberculosis infection in sheep flocks in southern Norway. Acta Vet. Scand 30, 107-108.

Kuria, J.K.N. and Nagattia, T.A. (1990): Caseous lymphadenitis of sheep and goats in Kenya. Bull. Anim. Health prod. Afr. 38: $15-18$.

Laven, R.A.; Fishwick, J.C; Pritchard, G.C. and Jackson, P.G.C. (1997): Generalised Caseous lymphadenitis. Vet. Rec., 140, pp 479.

Lopez, J.F.; Wong, F.M. and Quesada, J. (1966): Corynebacterium pseudotuberculosis. First case of human infection. Am. J. Clin. Pathol. 46: 562-567.

Magdy, H.AL-Gaabary; Salama A. Osman and Atef F. Oreiby (2009): Caseous lymphadenitis in sheep and goats: Clinical, epidemiological and preventive studies. Small Ruminant Research 87: 116-121.

Fontaine, M.C. and Baird, G.J. (2008): Caseous lymphadenitis. Small Ruminant Research 76: 42-48.

Fontaine, M.C. and Baird, G.J. (2008): Caseous Lymphadenitis. Small Ruminant Research 76: 42-48.

Miers, K.C. and Ley, W.B. (1980): Corynebacterium pseudotuberculosis infection in the horse: study of 117 clinical cases and consideration of etiopathogenesis. J. Am. Vet. Med. Assist. 177: 250-253. 
Mills, A.E.; Mitchell, R.D. and Lim, E.K. (1997): Corynebacterium pseudotuberculosis is a cause of human necrotising granulomatous lymphadenitis. Pathology 29: 231-233

Moller, K.; Agerholm, JS.; Ahrens, P.; Jensen, NE. and Nielsen, TK. (2000): Abscess disease, Caseous lymphadenitis, and pulmonary adenomatosis in imported sheep. J. Vet. Med. B Infect Dis Vet. Public. Health. FEB; 47 (1) 55-62.

Mubarak, M.; Bastawrows, A.F.; Abdel-Hafeez, M.M. and Ali, M.M. (1999): Caseous lymphadenitis of sheep and goats in Assiut farms and abattoirs. Assiut Vet. Med. J. 42: 89-112.

Musa, M.T. (1998): Lymphadenitis in sheep and goats in Sudan. Revue d'Elevage et de Medicine veterinaire des pays Tropicaux 51: 109-111.

Paton, M.W.; Collett, M.G. and Pepin, M. (2005): Corynebacterium pseudotuberculosis infections. In: Coetzer, J.A.W. and Tustin, R.C. (eds) infectious Diseases of Livestock, Volume 3, $2^{\text {nd }}$ end. Oxford University Press, Cape Town, pp. 1917-30

Paton, M.W.; Rose, I.R.; Hart, R.A.; Sutherland, S.S.; Mercy, A.R.; Ellis, T.M. and Dhaliwal, J.A. (1994): New infection with Corynebacterium pseudotuerculosis reduces wool production. Aust. Vet. J. 71: 47-49.

Paton, M.W.; Walker, S.B.; Rose, I.R. and Watt, G.F. (2003): Prevalence of caseous lymphoadenitis and usage of Caseous lymphadenitis vaccines in sheep flocks. Aust. Vet. J. 81: 91-95.

Paule, B.J.A.; Meyer, R.; Mouracosta, L.F.; Bahia, R.C.; Carmiati, R.; Regis, L.F.; Vale, V.L.C.; Freire, S.M.; Nascimento, L.; Schaer, R. and Azevedo, V. (2004): Three phase partitioning as an efficient method for extraction concentration of immunoreactive excreted secreted proteins of Corynebacterium pseudotuberculosis. protein Expr. Purif. 34: 311-316.

Peel, M.M.; Palmer, G.G.; Stacpoole, A.M. and Kerr, T.G. (1997): Human lymphadenitis due to Corynebacterium pseudotuberculosis: report of ten cases from Australia and review. Clin. Infect. Dis. 24: 185-191.

Poonacha, K.B. and Donahue, J.M. (1995): Abortion in a mare associated with Corynebacterium pseudotuberculosis infection. J.Vet. Diagn. Invest. 7: 563-564.

Pegram, R.G. (1973): An unusual form of lymphadenitis in sheepand goats in the smoali democratic republic, Springer Netherlands, 
Tropical Animal Health and Product, Volume 5, Number $1 /$ 1973, March, 35-39.

Jordan, R.M. (2008): Sheep Diseases, University of Minnesota, North Central Regional Extension Publication 379.

Rue Jensen and Brinton L. (1982): Swwift Diseases of sheep. philadelphia.

Schreuder, B.E.C.; ter Laak, E.A. and Dercksen, D.P. (1994): Eradication of caseous lymphadenitis in sheep with the help of a newly developed Elisa technique. Veterinary Record 135: 174-176.

Severini, M.; Ranucci, D.; Miraglia, D. and Cenci goga, B.T. (2003): Pseudotuberculosis in sheep as a concern of veterinary public health. Veterinary Research Communities 27: 315-318.

Shpigel, N.Y.; Elad, D.; Yeruham, I.; Winkler, M. and Saran, A. (1993): An outbreak of Corynebacterium pseudotuberculosis infection in an Israeli dairy herd. Vet. Rec. 133: 89-94.

Stanford, K.; Brogden, K.A.; McClelland, L.A.; Kozub, G.C. and Audibert, F. (1998): The incidence of caseous lymphadenitis in Alberta sheep and assessment of impact by vaccination with commercial and experimental vaccines. Can. J. Vet. Res. 62: $38-43$.

Stanford, K.; Brogden, K.A.; McClelland, L.A.; Kozub, G.C. and Audibert, F. (1998): The incidence of Caseous hymphadenitis in Alberta sheep and assessment of impact by vaccination with commercial and experimental vaccines. Canadia J. Vet. Res., 62, 1: 38-43.

Stoops, S.G.; Renshaw, H.W. and Thilsted, J.P. (1984): Ovine caseous lymphadenitis: disease prevalence, lesion distribution, and thoracic manifestations in a population of mature culled sheep from western United States. Am. J. Vet. Res. 45: 557-561.

Sunil, V. (2006): Control of caseous lymphadenitis in sheep: risk factors for disease and validation of an interferon gamma assay. M.V.SC. Thesis, Faculty of Graduate Studies of the University of Guelph.

Thomas, R. and Thedford, DVM. (1990): Sheep health handbook a field guide for producers with limited veterinary services. A winrock International informational services publication. printed in collaboration with agricultural experiment station division of agriculture University of arkansas. 
Walker, J.; Jackson, H.; Brandon, MR. and Meeusen, E. (1991): Lymphocyte subpopulation in pyogranulomas of caseous lymphadenitis. Clin exp immunol. Oct., 86 (1): 13-8.

Williamson, LH. (2001): Caseous lymphadenitis in small ruminants. Vet. clin north am food anim pract. Jul, 17 (2): 359-371,VII.

Yeruham, I.; Elad, D.; Van Ham, M.; Shpigel, N.Y. and Perl, S. (1997): Corynebacterium pseudotuberculosis infection in Israeli cattle: clinical and epidemiological studies. Vet. Rec. 140: 423-427.

Zaitoun, A.M. and Ali, H.S. (1999): Clinical and experimental pseudotuberculosis on a multiple ages sheep and goats flock with control trials via treatment and BCG vaccination. Assiut Vet. Med. J. 42: 239-259.

Zaitoun, A.M. and Bayoumi, A.H. (1994): Some epidemiological studies on ovine pseudotuberclosis. Assiut Vet. Med. J. 31: 238-250.

Zaki, M.M. and Abdel-Hamid, Y.M. (1974): A comparative study of invitro and in-vivo test for Caseous lymphadenitis. Res. Vet. Sci., 16: 167-170. 